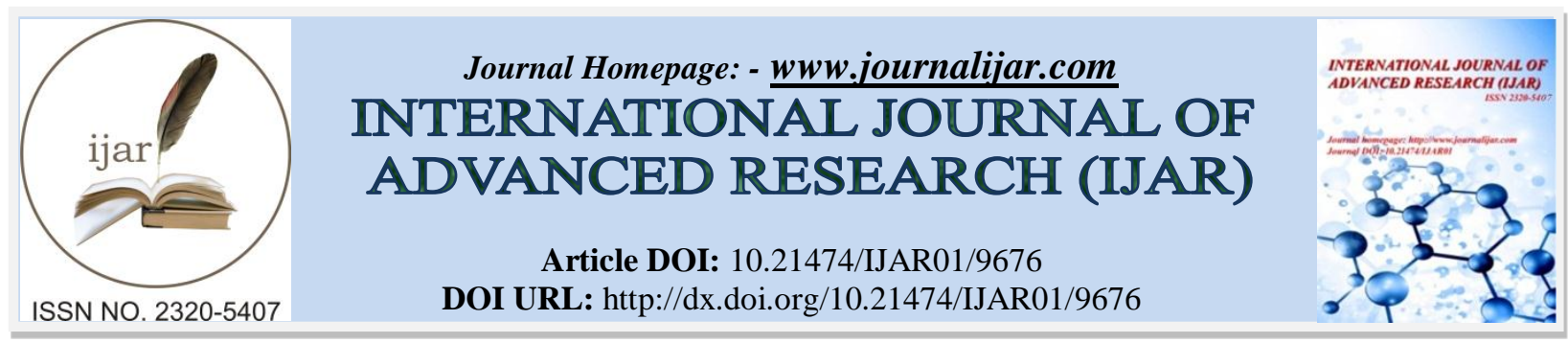

RESEARCH ARTICLE

\title{
LEARNING STRATEGIES FOR UNIVERSITY STUDENTS IN THE CITY OF SAN FRANCISCO DE CAMPECHE.
}

Karen Adriana Escudero González ${ }^{1}$ and Ana Rosa Can Valle ${ }^{2}$.

1. Intern of the Master in Educational Management of the National Pedagogic University.

2. Professor and researcher of the Faculty of Nursing of the Autonomous University of Campeche.

\section{Manuscript Info}

Manuscript History

Received: 06 July 2019

Final Accepted: 08 August 2019

Published: September 2019

\begin{abstract}
Education is an important factor for a country's development; where teachers should know and use teaching-learning strategies; however, there are various research that has found that some educators don't know, or practice, or apply them; hindering meaningful learning in students.

Objective: Identify learning strategies in college students.

Method: This research has a qualitative approach, descriptive type Subjects: 0 college students.

Instrument: The questionnaire applied was learning strategies. Results:In the different sections the students have their say in the following statements attitude to learning 69 students felt true, in the area environmental factors 56 students express true, in the organization for study the students are constant for study, although 60 of them sometimes say, in the section methods for understanding a content 53 manifested true, in the section understanding of reading, 50 students refer true, in the field, strategy outline 62 students took true opinion, in the short strategy summary 71 opinion true and the strategy conceptual map the opinion of 70 students who expressed true is very significant and in some areas sometimes they will have to be attended to. Conclusion: In this research it should be consider the opinions students made to improve their quality in learning strategies, giving them other tools for improving education.
\end{abstract}

Copy Right, IJAR, 2019. All rights reserved.

\section{Introduction:-}

To educate, implies for all those who dedicate themselves to this noble task, a serious and responsible commitment to a work that requires obligatory disposition, knowledge, sensitivity and above all a full life of values, which will be transmitted with the daily example to those who taught and the social environment in which it is lived. Education is an important factor for a country's development; where teachers should know and use teaching-learning strategies; however, there is various research that has found that some educators don't know or practice, or apply them; hindering meaningful learning in students (Hernández, 1999).

The conceptualization of the disaggregated teaching-learning process in all its components and nuances, focusing the skills of the learner and the learner, to focus later on didactic planning and its characteristics. This research aims to support students during their school trajectory and give them the necessary teachings for a better understanding.

Corresponding Author:-Karen Adriana Escudero González.

Address:-Intern of the Master in Educational Management of the National Pedagogic University. 
Learning strategies are mental activities or operations used to facilitate knowledge acquisition, involve the application of cognitive tools to perform specific tasks, examples: conceptual maps, organizers, metaphors, mnemonics, analogies, among others.

Learning strategies are cognitive operations or activities that facilitate and develop the various school learning processes. Through strategies we can process, organize and retain informational material to learn, in addition, they are learned as part of a training (Beltrán 1995).Beltran, (1995), presents a classification of strategies for the development of cognitive skills and abilities, which is selected for the teaching-learning process: support strategies: improves self-concept, develops attitudes, enhances motivation; processing strategies: repetition, self-testing, underlining, organization, schematics, concept maps, heuristic scravs; personalization strategies: reflexic critical thinking, flexibility of thought, creativity, new ideas, new approaches; metacognition strategies: provide a knowledge of the task, what it is and what is known about it.

Dansereau (1985) defines them as an integrated sequence of procedures or activities that are erected for the purpose of facilitating the acquisition, storage and/or use of information. They are also considered sequences of procedures or plans oriented towards meeting goals and involve what behaviors the student performs during their learning process. The term strategy is increasingly used in pedagogical literature, despite its multiple meanings and interpretations. The advantages that its proper use can offer in educational processes are indisputable.

Faced with an ever-changing world of change, education remains the strategic pedagogical response to equip students with intellectual tools, which will allow them to adapt to the incessant transformations of the world of work and the expansion of the world of work knowledge. Therefore, the need for planning and using teaching strategies that enhance thoughtful learning and education to cope with the changes, uncertainty and dynamics of today's world is now underpinned, among other aspects by: 1) the dizzying growth of information and the infinitude of human knowledge; (2) the accelerated advancement of information and communications technologies; 3) the projection of lifelong learning, which puts the teacher in the face of the need to prepare for themselves and be able to direct their own learning, through conscious mastery of their resources to generate strategies and define, use and evaluate the procedures necessary to solve problems, taking into account the conditions of the medium and your own; 4) the new ways of learning, based on discovery and participation, with more flexible systems, that allow to incorporate the technological tools to search for information and share problems, projects and tasks in daily life.

\section{Learning Strategies are defined by different authors:}

Oxford, (1990), are specific actions taken by the student to make learning easier, more enjoyable, self-directed and transferable to new situations.

Castellanos and Others, (2002), says that the strategies comprise the plan deliberately designed with the goal of achieving a certain goal, through a set of actions that is executed in a controlled manner.

Monereo, (1994), learning strategies are decision-making processes in which students choose and retrieve, in a coordinated manner, the knowledge they need to meet a certain demand or goal, depending on characteristics of the educational situation in which the action occurs. In the teaching-learning process, it is important that these and other strategic elements are addressed, reinforcing their effective implementation whenever possible. In this regard, it points out how strategies change according to the objectives, content and context of realization and the importance of encouraging students to implement and integrate the strategic resources available to them.

\section{Method:-}

The goal of research is to identify learning strategies in university students. It has a qualitative approach, with a descriptive design, these studies serve to specify important properties of people, groups, communities or any other phenomenon that is subjected to analysis, not experimental (Hernández et al., 2014). The sample consisted of 80 university students, the questionnaire was applied learning strategies, this consists of 8 sections with a total of 44 items: I. Attitude to Learning (AA), II. Environmental Factors (FA), III. Organization for study, IV. Methods for Understanding a Content (MCC), V. Reading Understanding (CL), VI. Schema Strategy (EE), VII. Summary Strategy (MS), VIII. Conceptual Map Strategy (EMC), students were told how to answer the questionnaire and given directions on how to solve it. The database was analyzed in the Microsoft Excel program and the following results were obtained. 


\section{Results:-}

After analyzing the data, the following results are presented below.

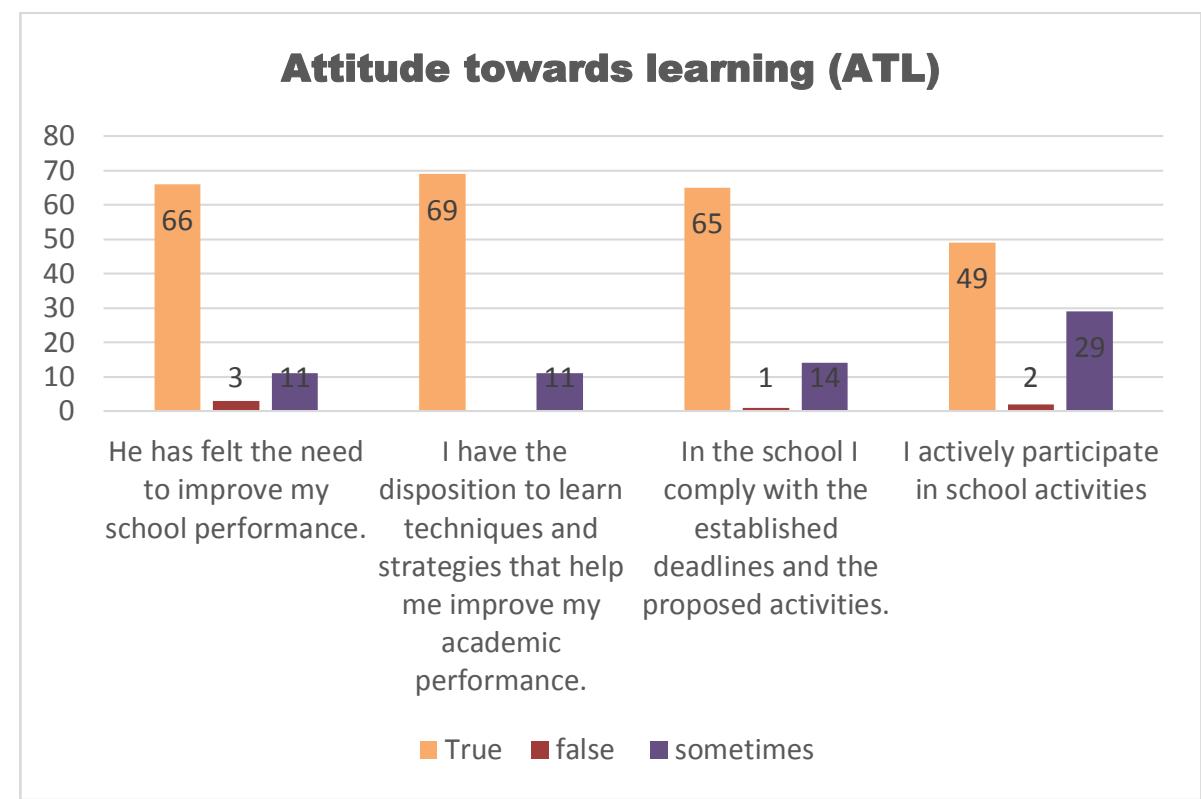

Graph 1:-Attitude towards learning (ATL)

In graph 1. Attitude to learning: in the sense of the need to improve school performance 66 students felt true, 3 of them say false and 11 of them sometimes refer; in the question, I have a willingness to learn techniques and strategies to help me improve my economic performance, 69 commented true and 11 said a few times; in the statement, in the school met the deadlines and the proposed activities, 65 students felt true, 14 of them expressed a few times and one student said false; In the statement I actively participated in school activities, 49 students expressed true, 2 false and 29 commented a few times.

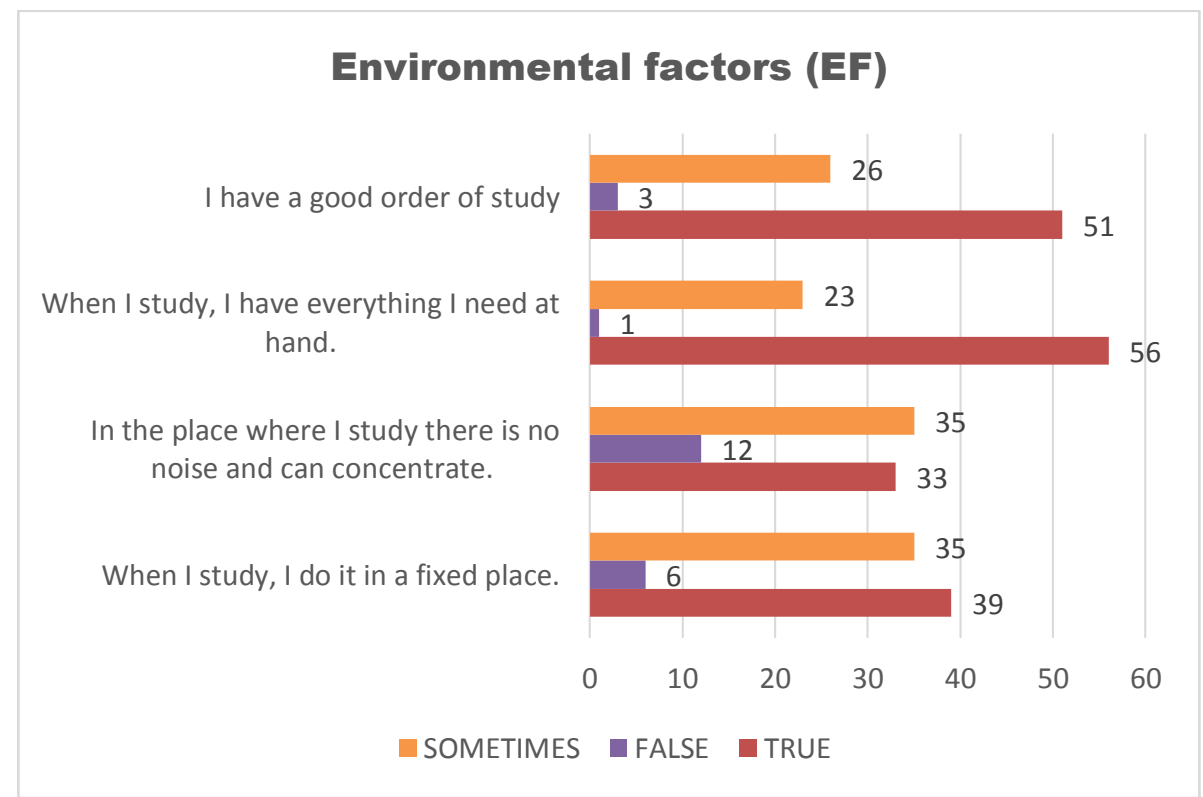

Graph 2:-Environmental factors (EF)

In graph 2, environmental factors: in the statement when I study, I do it in a fixed place, 39 students commented true, 6 said false and 35 expressed a few times; in the statement, in the place where there is no noise and I can 
concentrate, 33 students refer true, 12 manifest false and 35 sometimes commented; in the indicator when I study, I have at hand everything I need, 56 students comment true, 23 of them said a few times and one false comment; When referring, I have well-ordered the place of study 51 students express true, 26 opinions sometimes and 3 expressed false.

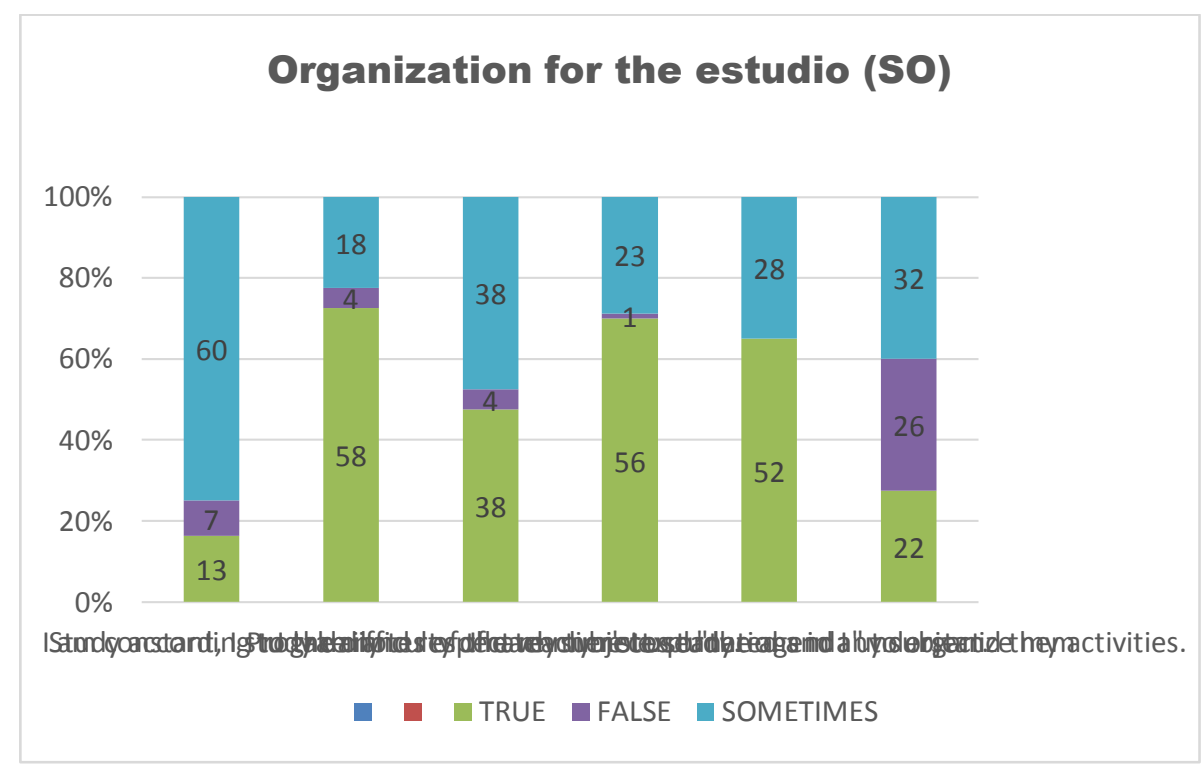

Graph 3:-Organization for the estudio (SO)

In graph 3, organization for the study: I am constant, study daily, 13 students comment true, 7 say false and 60 express sometimes; study according to the difficulty of each subject, 58 expressed true, 4 of them say false and 8 opined a few times; program and respect my time to study, 38 of the students expressed true, 4 thought false and 38 stated a few times; I take notes of the teacher's explanations in any subject, 56 students refer true, 1 false dice and 23 expressed a few times; I have my notes sorted and I understand them, 52 students thought true and 28 say sometimes; I use "the agenda" to organize my activities, 22 students stated true, 26 say false and 32 expressed a few times.

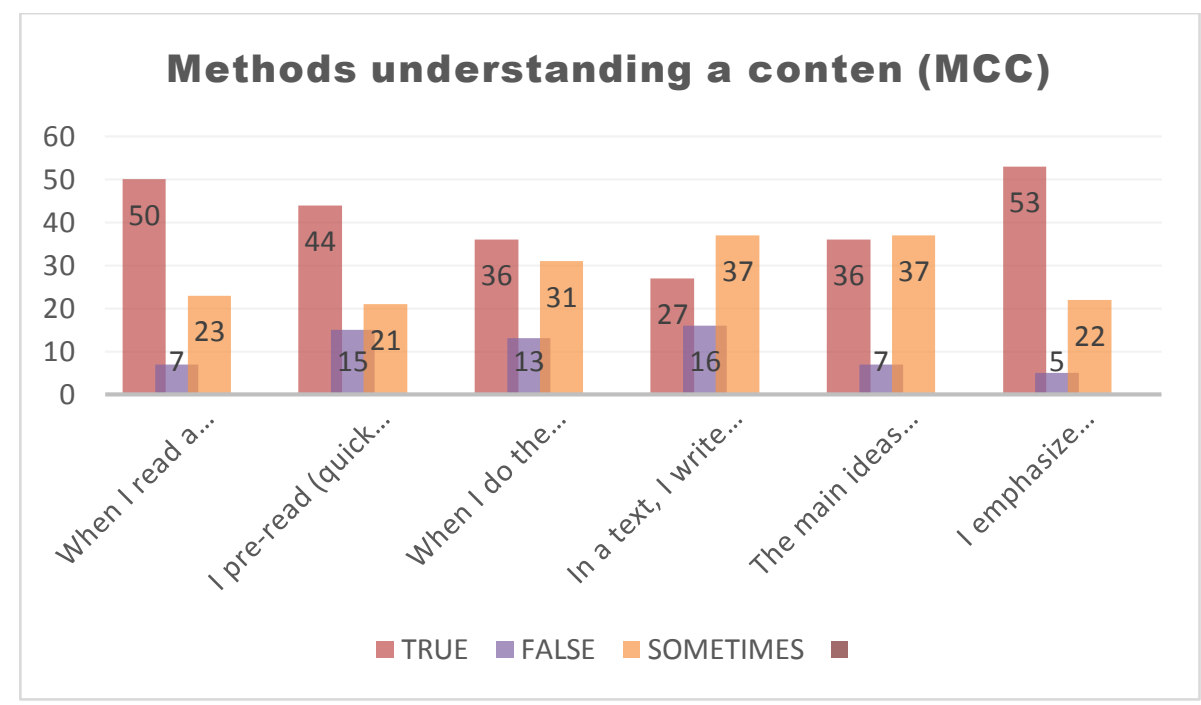

Graph 4:-Methods for understanding a content (MCC)

In this graph 4. Methods for understanding a content: it is observed that the utterance, when I read a text, I use a specific method to better understand the content, 50 students thought true, 7 said false and 23 expressed sometimes; in the indicator, I do a pre-reading (quick reading) before reading any text, 44 students commented true, 15 suggest 
false and 21 say sometimes, on the question, when I do the sympathetic reading, I ask myself questions like: Who', How?, where, why, what? To better understand the content, 36 students expressed true, 13 thought false, and 31 stated a few times; the main ideas that I point out, I use them later to make schematics, abstracts or conceptual maps, 36 students think true, 7 comment false and 37 sometimes manifest; emphasizing the main ideas of secondary ideas, 53 students commented true, 5 say false and 22 express sometimes.

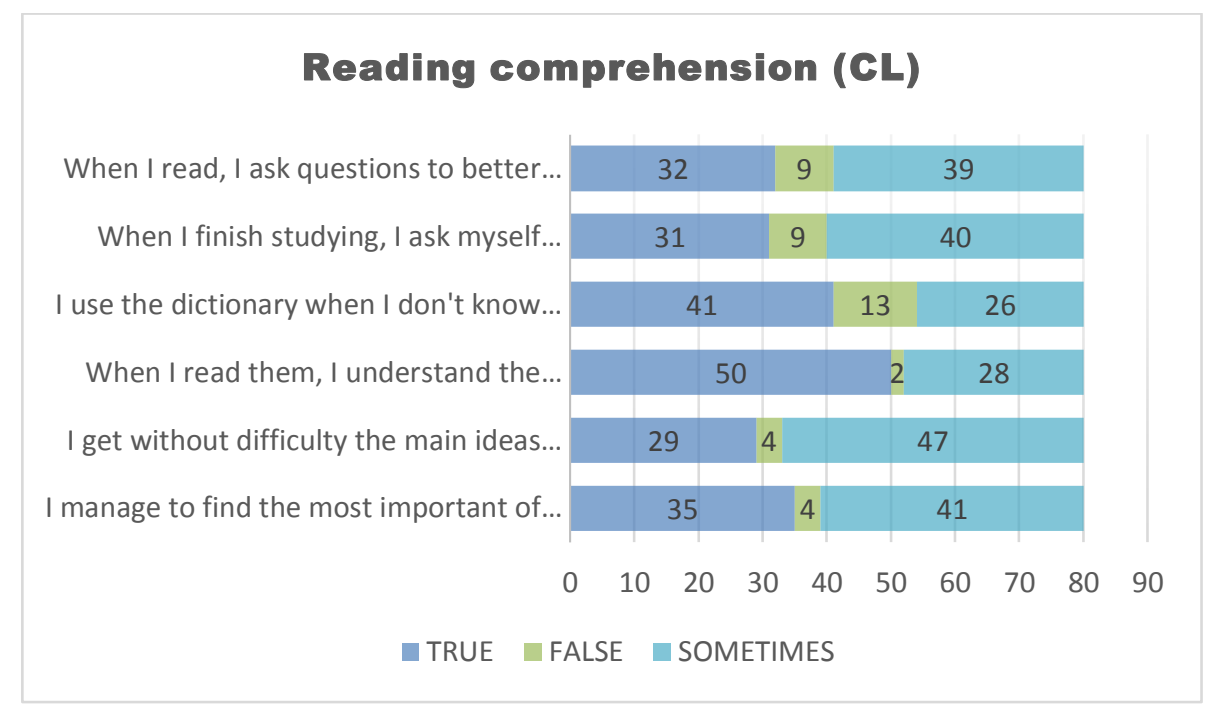

Graph 5:-Reading comprehension (CL)

In chart 5, understanding of reading: in the statement, I manage to find the most important thing of a subject without difficulty, 35 students expressed true, 4 opinioned false and 41 of them say sometimes; I get the main ideas and secondary ideas of a text without difficulty, 290 students spoke true, 4 expressed false and 47 sometimes took a say; in the question, when I read to them, I understand the information presented, 50 students expressed true, 2 opinions false and 28 sometimes referred; I use the dictionary when the meaning of some word was not meant, 41 students thought true, 13 commented falsely and 26 stated a few times; As I finished studying, I ask myself questions to find out how much I learned and observe what I lack, 31 students expressed true, 9 opinions false and 40 commented a few times; when I read, I ask myself questions to better understand reading, 32 thought true, 9 expressed false, and 39 stated a few times.

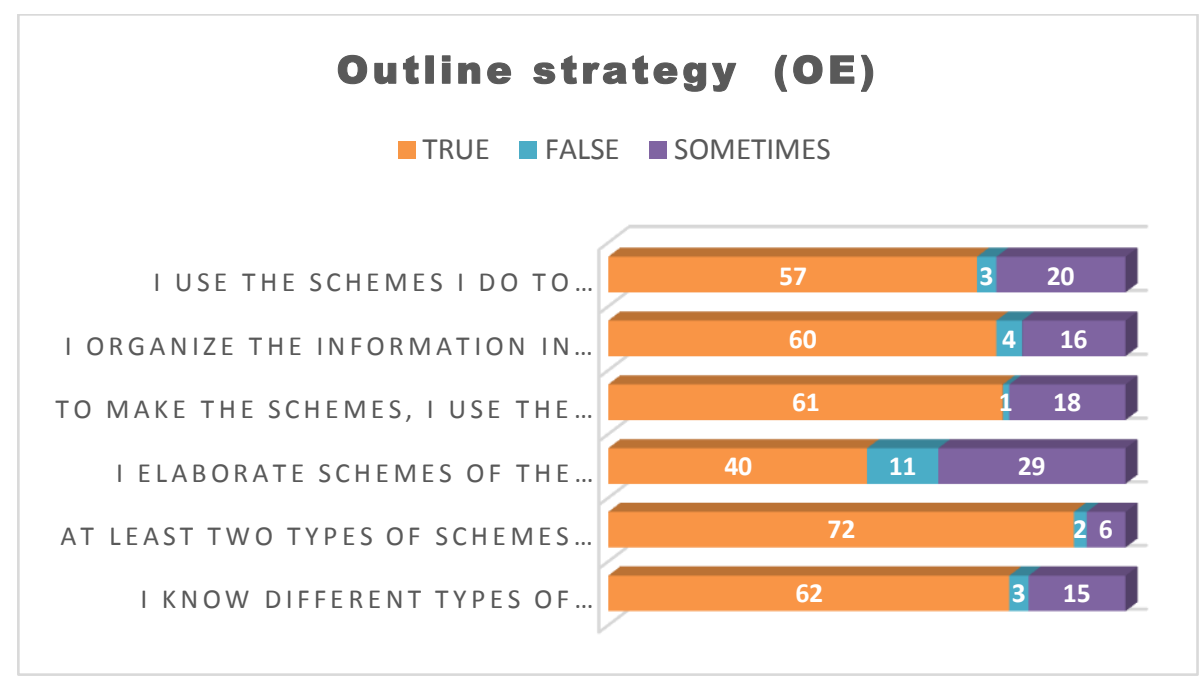

Graph 6:-Outline strategy

In graph 6. Schema strategy; in the statement I know different types of scheme 62 students felt true, 3 false and 15 manifested a few times; the indicator developed at least two types of schemes, 72 students expressed true, 2 false and 6 sometimes commented; in the question, I outline the subjects I should study, 40 students felt true, 11 false and 
29 of them sometimes opinioned; to make the schemes, I use the underline and the side notes, 61 students thought true, 1 stated false and 18 suggested a few times; I organize the information in order of importance to carry out the scheme without difficulty, 60 thought true, 4 of them false and 16 stated a few times; I use the schemes I do to review and memorize what I have to study, saving time and effort, 57 students commented true, three opinioned false and 20 expressed a few times.

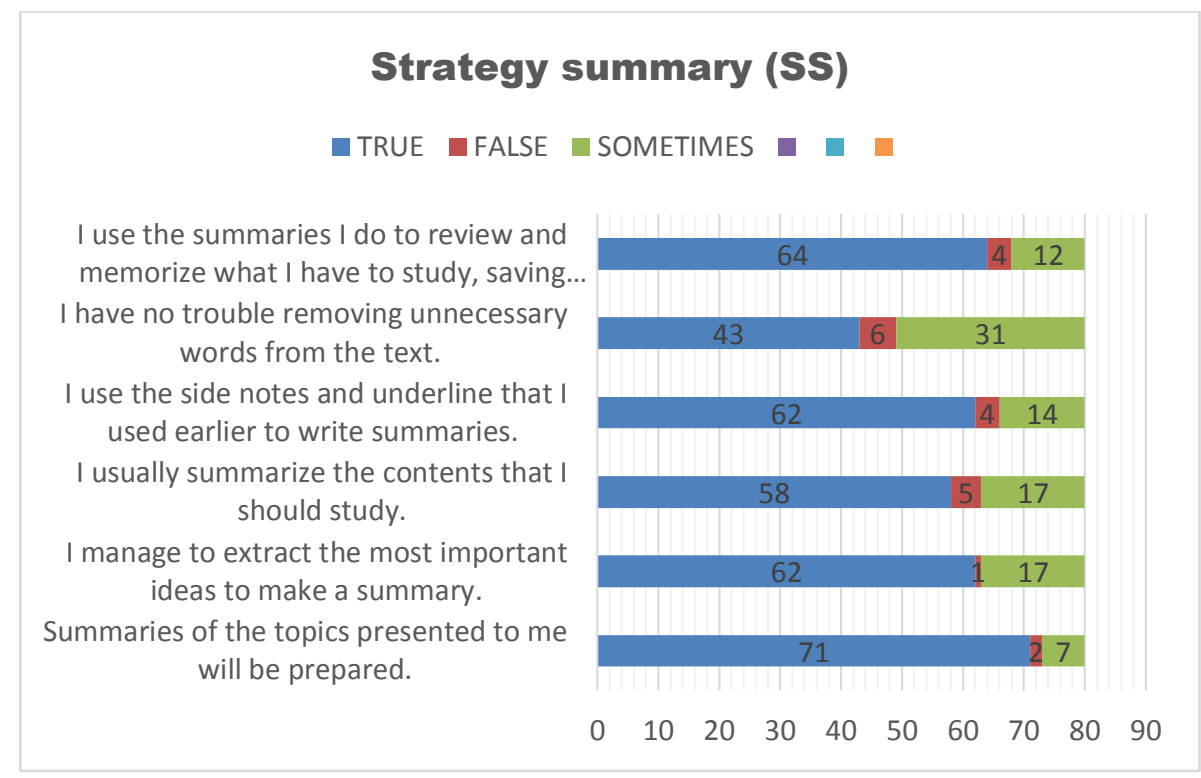

Graph 7:-Stratety sumaría (SS)

In graph 7. Summary strategy: summaries of the topics presented were prepared, 71 students felt true, 2 opinions were false and 7 times; in the statement, I manage to extract the most important ideas to make a summary, 62 students opinioned true, 1 opinion false and 17 times; I usually make summaries of the content I have to study, 58 students expressed true, 5 say false and 17 commented a few times; in the question, I use the side notes and the underline that I used earlier to prepare abstracts, 62 students thought true, 4 of them say false and 14 stated a few times; I don't have a hard time removing the unnecessary words from the text, 43 students commented true, 6 misspoken and 31 expressed a few times; I use the summaries I do to review and memorize what I have to study, saving time and effort, 64 students expressed true, 4 of them say false and 12 comment sometimes.

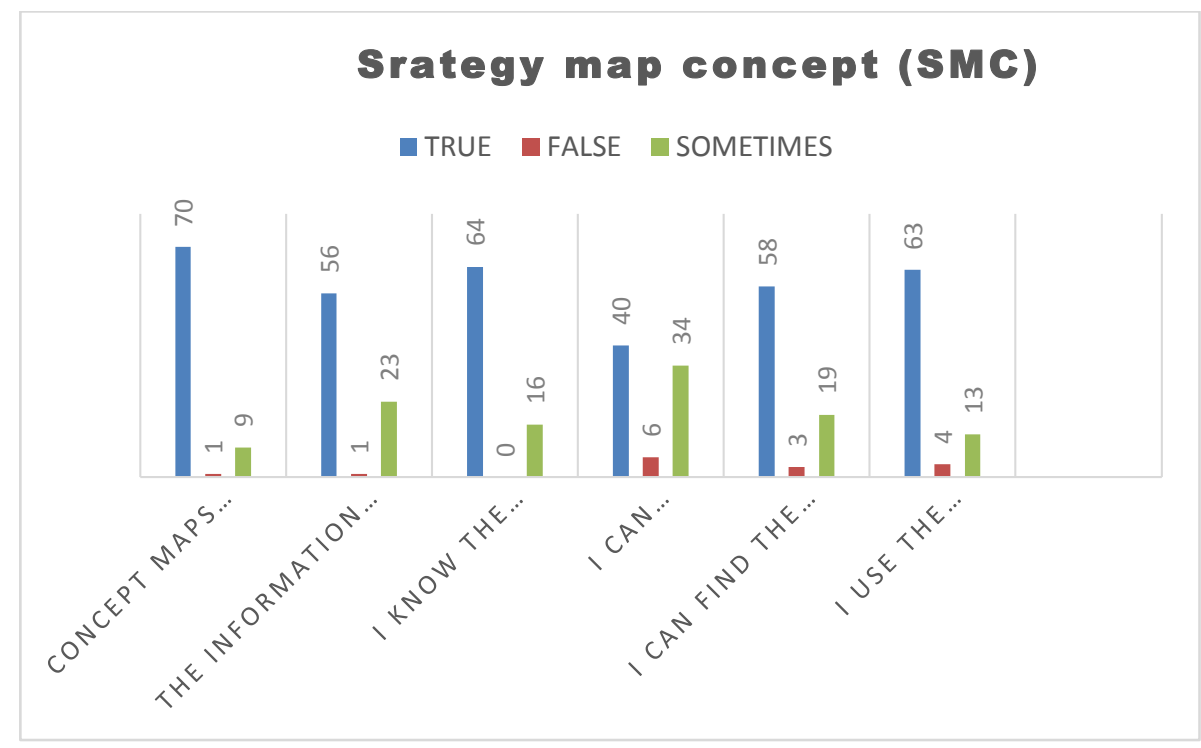

Graph 8:-Strategy map concept (SMC) 
In graph 8. Strategy conceptual map: in the statement, conceptual maps were prepared to study, 70 students thought true, 1 dice false and 9 expressed a few times; information from a study text to make a conceptual map is hierarchically sorted to make a conceptual map, 56 students felt true, 1 false dice and 23 commented at times; I know the structure of conceptual maps, 64 expressed true and 16 say sometimes; in the indicator, I can differentiate a concept from a preposition, 40 comment true, 6 say false and 34 expressed a few times; I can find the key concepts of the text, 58 students thought true, 3 say false and 19 comment sometimes; I use the conceptual maps I do to review and memorize what I have to study, saving time and effort, 63 students say true, 4 say false and 13 expressed sometimes.

\section{Conclusions:-}

In conclusion, this research should consider the opinions that students made to improve their quality in learning strategies, give them other tools for improving their education, in the sections where they obtained false response or sometimes, it is necessary to restructure strategies in some areas where students require support for better their strategies, it is suggested to reinforce students with courses of study techniques and learning strategies.

\section{References:-}

1. Beltrán Llera, J. (1995) Psychology of Education. Madrid. Eudema (Editions of the Compluntese University of Madrid).

2. Dansereau (1985). Quoted in Herrera Cubas, J, (1997). Cognitive and metacognitive strategies in the elaboration of the written message. Two-way English-Spanish study. Spanish. Dissertation. La Laguna: Publications Service of the Universidad de La Laguna.

3. Hernández Sampieri, R., Fernández Collado, C., \& Baptista Lucio, P. (2014). Research Methodology. Edit. McGaw-Hill.

4. Kingler, C and G. Vadillo (1997). Cognitive psychology. Strategies in teaching practice.

5. Oca Mountains, R, N; Machado, R, E. (2011). Teaching strategies and teaching-learning methods in higher education. Scielo Magazine. Rev Hum Med Vol 11. No. 3. Available http://scielo.sld.cu/scielo.php?pid=S1727$81202011000300005 \&$ script $=$ sci_arttext\&tlng=pt

6. Morales, C, A, the ABC of the Teacher (2002). First edition. Universidad Autónoma de Campeche and Universidad de Ciencias Comerciales Nicaragua. Editorial Direction of Educational Services Support. Autonomous University of Campeche. Campeche

7. Sánchez, S, M. (2013). Academic Tutoring. Edited by the Autonomous University of Mexico. Faculty of Higher Studies Itzcala. 